\title{
Parapedobacter soli sp. nov., isolated from soil of a ginseng field
}

\author{
Myung Kyum Kim, ${ }^{1}$ Young-Ae Kim, ${ }^{1}$ Yu-Jin Kim, ${ }^{1}$ Nak-Kyun Soung, ${ }^{2}$ \\ Tae-Hoo Yi, ${ }^{1}$ Se-Young Kim ${ }^{1}$ and Deok-Chun Yang $^{1}$ \\ ${ }^{1}$ Korean Ginseng Center and Ginseng Genetic Resource Bank, Kyung Hee University, \\ 1 Seocheon-dong, Kiheung-gu Yongin, Kyunggi-do 449-701, South Korea \\ ${ }^{2}$ Laboratory of Metabolism, Center for Cancer Research, National Cancer Institute, National \\ Institutes of Health, Bethesda, MD 20892, USA
}

Correspondence

Deok-Chun Yang

dcyang@khu.ac.kr
The family Sphingobacteriaceae was proposed by Steyn et al. (1998). Typical features of the family Sphingobacteriaceae are the possession of sphingolipids, the presence of the MK-7 quinone system, a low $\mathrm{G}+\mathrm{C}$ content (37-44 mol\%) and the presence of the distinctive fatty acid iso- $\mathrm{C}_{15: 0} 2-$ $\mathrm{OH}$. At the time of writing, the family Sphingobacteriaceae consists of four genera, Sphingobacterium (Yabuuchi et al., 1983), Pedobacter (Steyn et al., 1998), Olivibacter (Ntougias et al., 2007) and Parapedobacter (Kim et al., 2007).

In a series of studies, we attempted to isolate microorganisms from soil samples in order to investigate the community structure, using a culture-dependent method. In this study, a strain was isolated from soil from a ginseng field in Daejeon in South Korea and was then characterized by means of a polyphasic approach designed to determine the precise taxonomic position of this organism, strain DCY $14^{\mathrm{T}}$. This approach included phylogenetic analyses based on 16S rRNA gene sequences, analysis of genomic relatedness and determination of the chemotaxonomic and phenotypic properties. The results obtained in this study indicated that DCY $14^{\mathrm{T}}$ represents a novel member of the family Sphingobacteriaceae.

Strain DCY $14^{\mathrm{T}}$ was isolated from soil from a ginseng field near Daejeon, using direct plating onto R2A agar (Difco). Single colonies on these plates were purified by transferring

The GenBank/EMBL/DDBJ accession number for the 16S rRNA gene sequence of strain $\mathrm{DCY} 14^{\top}$ is EF151805. them onto new plates and subjecting them to an additional incubation for 5 days at $30{ }^{\circ} \mathrm{C}$. The purified colonies were tentatively identified by means of partial $16 \mathrm{~S}$ rRNA gene sequences.

Cell morphology and motility were investigated with a Nikon light microscope (magnification, $\times 1000$ ), using cells allowed to grow for 3 days at $30{ }^{\circ} \mathrm{C}$ on $\mathrm{R} 2 \mathrm{~A}$ agar. Gram reactions were determined using the non-staining method, as described by Buck (1982). Oxidase activity was evaluated from the oxidation of $1 \% p$-aminodimethylaniline oxalate. Catalase activity was determined from measurements of bubble production after the application of a $3 \%(\mathrm{v} / \mathrm{v})$ hydrogen peroxide solution. Growth at a variety of temperatures $\left(4,15,25,30,37\right.$ and $\left.42{ }^{\circ} \mathrm{C}\right)$ was assessed on $\mathrm{R} 2 \mathrm{~A}$ agar and growth at a variety of $\mathrm{pH}$ values was assessed in $\mathrm{R} 2 \mathrm{~A}$ broth. Growth at $30{ }^{\circ} \mathrm{C}$ on nutrient agar, trypticase soy agar and MacConkey agar was also evaluated. The API 20NE and API ID 32GN microtest systems were employed in these tests, according to the recommendations of the manufacturer (bioMérieux).

Isoprenoid quinones were extracted with chloroform/ methanol $(2: 1, \mathrm{v} / \mathrm{v})$, purified by TLC and subsequently analysed by HPLC, as described previously (Collins \& Jones, 1981; Shin et al., 1996). For fatty acid methyl ester analysis, the strain was allowed to grow on trypticase soy agar for $48 \mathrm{~h}$ at $30{ }^{\circ} \mathrm{C}$ and then two loops of the wellgrown cells were harvested. Fatty acid methyl esters were prepared, separated and identified with the Sherlock 
Table 1. Phenotypic characteristics of strain DCY $14^{\top}$ and related type strains

Strains: $1, \mathrm{DCY} 14^{\mathrm{T}}$ (data from this study); 2, Parapedobacter koreensis Jip $14^{\mathrm{T}}$ (data from this study); 3, Olivibacter sitiensis AW $-6^{\mathrm{T}}$ (Ntougias et al., 2007); 4, Pedobacter heparinus LMG $10339^{\mathrm{T}}$ (Steyn et al., 1998); 5, Sphingobacterium spiritivorum LMG $8347^{\mathrm{T}}$ (Steyn et al., 1998). All of the strains are positive for the presence of catalase and oxidase and for the assimilation of D-glucose and sucrose. All of the strains are negative for the Gram-stain reaction and for the assimilation of acetate, citrate and L-proline. The following tests were positive for all strains (no data available for $O$. sitiensis AW- $6^{\mathrm{T}}$ ): $N$-acetyl- $\beta$ glucosaminidase, acid phosphatase, alkaline phosphatase, $\alpha$-glucosidase, $\beta$-galactosidase (PNPG), leucine arylamidase, D-mannose, mannitol, salicin and growth on nutrient agar. All of the strains were negative for indole production, protease (gelatin hydrolysis) and L- $\alpha$ alanine. +, Positive; -, negative; v, variable; ND, no data available.

\begin{tabular}{|lccccc|}
\hline Characteristic & $\mathbf{1}$ & $\mathbf{2}$ & $\mathbf{3}$ & $\mathbf{4}$ & $\mathbf{5}$ \\
\hline Motility & - & - & - & Gliding & - \\
Growth at: & & & & & \\
$4{ }^{\circ} \mathrm{C}$ & - & - & + & $\mathrm{ND}$ & - \\
$37{ }^{\circ} \mathrm{C}$ & + & + & + & - & $+^{*}$ \\
$42{ }^{\circ} \mathrm{C}$ & - & + & + & - & - \\
Enzyme activity & & & & & \\
Chymotrypsin & - & + & $\mathrm{ND}$ & - & $+^{*}$ \\
Cystine arylamidase & - & + & $\mathrm{ND}$ & - & $+^{*}$ \\
Esterase (C8) & + & - & $\mathrm{ND}$ & + & + \\
$\alpha$-Fucosidase & - & - & $\mathrm{ND}$ & - & $+^{*}$ \\
$\alpha$-Galactosidase & + & + & $\mathrm{ND}$ & - & $+^{*}$ \\
$\beta$-Glucosidase & + & + & $\mathrm{ND}$ & - & $+^{*}$ \\
$\beta$-Glucuronidase & - & - & $\mathrm{ND}$ & - & $+^{*}$ \\
Lipase (C14) & - & - & $\mathrm{ND}$ & - & $+^{*}$ \\
$\alpha$-Mannosidase & + & - & $\mathrm{ND}$ & - & $+^{*}$ \\
Trypsin & - & + & $\mathrm{ND}$ & - & $+^{*}$ \\
Urease & - & - & $\mathrm{ND}$ & - & $+^{*}$ \\
Valine arylamidase & - & + & $\mathrm{ND}$ & - & $+^{*}$ \\
Assimilation of: & & & & & \\
L-Arabinose & + & - & $\mathrm{ND}$ & + & - \\
L-Fucose & - & + & $\mathrm{ND}$ & + & - \\
Maltose & + & + & - & + & + \\
Melibiose & + & - & $\mathrm{ND}$ & + & + \\
Rhamnose & + & - & $\mathrm{ND}$ & + & + \\
Ribose & + & + & $\mathrm{ND}$ & - & - \\
Inositol & - & + & - & - & - \\
Sorbitol & + & + & + & + & - \\
L-Histidine & - & - & + & - & - \\
L-Serine & - & + & - & $\mathrm{V}$ & - \\
Glycogen & + & - & $\mathrm{ND}$ & - & - \\
DNA G+C content & 50.1 & 45.6 & 45.6 & $42.3-43.0$ & 39.8 \\
$($ mol\%) & & & & & \\
\hline
\end{tabular}

${ }^{\star}$ Data from Takeuchi \& Yokota (1992).

Microbial Identification System (MIS; MIDI) (Sasser, 1990).

For the determination of $\mathrm{G}+\mathrm{C}$ content, genomic DNA of strain $\mathrm{DCY} 14^{\mathrm{T}}$ was extracted and purified with Qiagen
Table 2. Comparison of the cellular fatty acid profiles of strain DCY $14^{\top}$ and related type strains

Strains: $1, \mathrm{DCY} 14^{\mathrm{T}}$ (data from this study); 2, Parapedobacter koreensis Jip14 ${ }^{\mathrm{T}}$ (data from this study); 3, O. sitiensis AW-6 ${ }^{\mathrm{T}}$ (Ntougias et al., 2007); 4, Pedobacter heparinus LMG $10339^{\mathrm{T}}$ (Steyn et al., 1998); 5, S. spiritivorum LMG $8347^{\mathrm{T}}$ (Steyn et al., 1998). Values are percentages of total fatty acids; components making up more than $10 \%$ of the total fatty acids are highlighted in bold. For unsaturated fatty acids, the position of the double bond is located by counting from the methyl $(\omega)$ end of the carbon chain; cis isomers are indicated by the suffix $c$. tr, Trace amount; ECL, equivalent chain length; -, not detected/not reported.

\begin{tabular}{|c|c|c|c|c|c|}
\hline Fatty acid & 1 & 2 & 3 & 4 & 5 \\
\hline anteiso- $\mathrm{C}_{13: 0}$ & 11.4 & - & - & - & - \\
\hline $\mathrm{C}_{14: 0}$ & - & 1.1 & 0.5 & 1.1 & 1.0 \\
\hline $\mathrm{C}_{15: 0}$ & - & - & - & 1.1 & - \\
\hline $\mathrm{C}_{15: 0} 3-\mathrm{OH}$ & - & 1.7 & - & - & - \\
\hline anteiso- $\mathrm{C}_{15: 0}$ & 0.6 & - & - & $\operatorname{tr}$ & $\operatorname{tr}$ \\
\hline iso- $\mathrm{C}_{15: 0}$ & 29.3 & 33.6 & 29.3 & 28.2 & 30.1 \\
\hline iso- $\mathrm{C}_{15: 0} 3-\mathrm{OH}$ & 3.7 & 2.3 & 1.9 & 2.5 & 2.2 \\
\hline iso- $\mathrm{C}_{15: 1} \mathrm{~F}$ & - & - & 0.3 & - & - \\
\hline $\mathrm{C}_{15: 1} \omega 6 c$ & - & 1.1 & - & - & - \\
\hline$C_{16: 0}$ & 2.7 & 6.0 & 5.5 & 3.0 & 3.5 \\
\hline $\mathrm{C}_{16: 0}$ 10-methyl & - & 7.1 & - & - & - \\
\hline $\mathrm{C}_{16: 0} 2-\mathrm{OH}$ & - & 1.1 & 0.9 & - & - \\
\hline $\mathrm{C}_{16: 0} 3-\mathrm{OH}$ & 2.3 & 1.9 & 0.7 & 1.5 & 2.7 \\
\hline anteiso- $\mathrm{C}_{16: 0}$ & - & 0.5 & - & - & - \\
\hline $\mathrm{C}_{16: 1} 2-\mathrm{OH}$ & - & - & 0.6 & - & - \\
\hline $\mathrm{C}_{16: 1} \omega 5 c$ & - & - & 1.3 & 1.4 & $\operatorname{tr}$ \\
\hline anteiso- $\mathrm{C}_{17: 0}$ & 3.1 & - & - & - & - \\
\hline iso- $\mathrm{C}_{17: 0}$ & - & - & 0.4 & - & - \\
\hline iso- $\mathrm{C}_{17: 0} 3-\mathrm{OH}$ & 16.3 & 14.4 & 11.2 & 15.2 & 12.5 \\
\hline iso- $\mathrm{C}_{17: 1} \omega 9 c$ & 7.1 & - & 2.0 & 6.3 & 1.7 \\
\hline $\mathrm{C}_{18: 0}$ & 1.2 & - & - & - & - \\
\hline \multicolumn{6}{|l|}{ Summed features ${ }^{*}$} \\
\hline iso- $\mathrm{C}_{15: 0} 2-\mathrm{OH} / \mathrm{C}_{16: 1} \omega 7 c$ & 19.4 & 27.8 & 43.2 & 30.6 & 42.6 \\
\hline iso- $\mathrm{C}_{17: 1} \mathrm{I} /$ anteiso- $\mathrm{C}_{17: 1} \mathrm{~B}$ & 0.8 & - & 0.5 & - & - \\
\hline $\begin{array}{l}\mathrm{C}_{19: 1} \omega 11 c / \text { unknown ECL } \\
18.756\end{array}$ & 1.2 & - & - & - & - \\
\hline ECL 13.566 & - & 0.8 & 0.9 & 5.0 & $\operatorname{tr}$ \\
\hline ECL 16.580 & 1.1 & - & - & 1.0 & $\operatorname{tr}$ \\
\hline ECL 16.582 & - & 0.7 & 1.1 & - & \\
\hline
\end{tabular}

${ }^{*}$ Summed features are fatty acids that could not be separated by GLC with the Microbial Identification System (MIDI).

Genomic-tip system 100/G and was then enzymically degraded into nucleosides, as described previously (Tamaoka \& Komagata, 1984; Mesbah et al., 1989).

For $16 \mathrm{~S}$ rRNA gene sequencing, genomic DNA was extracted and purified with a genomic DNA isolation kit (Core Bio System). The 16S rRNA gene was amplified from the chromosomal DNA of strain DCY $14^{\mathrm{T}}$ using the universal bacterial primer set $9 \mathrm{~F}$ and $1512 \mathrm{R}$ (Weisburg et al., 1991) and the purified PCR products were sequenced by Genotec (Daejeon, Korea) (Kim et al., 2005). The full 
sequence of the 16S rRNA gene was compiled with SeqMan software, and the 16S rRNA gene sequences of the test strain were edited using the BioEdit program (Hall, 1999). The 16S rRNA gene sequences of related taxa were obtained from GenBank. Multiple alignments were performed with the CLUSTAL_X program (Thompson et al., 1997), evolutionary distances were calculated using the Kimura two-parameter model (Kimura, 1983) and the phylogenetic tree was constructed using the neighbourjoining method (Saitou \& Nei, 1987) in the MEGA2 program (Kumar et al., 2001). A bootstrap analysis (based on 1000 replicates) was conducted to obtain confidence levels for the branches of the phylogenetic tree (Felsenstein, 1985).

Strain DCY $14^{\mathrm{T}}$ was cultured on R2A agar at $30{ }^{\circ} \mathrm{C}$, yielding yellow, circular colonies. The strain was found to comprise aerobic, Gram-negative, non-motile, rod-shaped (0.8$1.0 \times 0.2-0.4 \mu \mathrm{m})$ bacterial cells. Strain DCY $14^{\mathrm{T}}$ grew at $15-37{ }^{\circ} \mathrm{C}$, but did not grow at 4 or $42{ }^{\circ} \mathrm{C}$. Physiological features of strain DCY $14^{\mathrm{T}}$ are summarized in the species description, and a comparison of selective characteristics with those of related type strains is shown in Table 1.

The cellular fatty acid profiles of strain DCY $14^{\mathrm{T}}$ and related taxa are shown in Table 2. The major cellular fatty acids in strain DCY $14^{\mathrm{T}}$ included the following: anteiso- $\mathrm{C}_{13: 0}$ $(11.4 \%)$, iso- $\mathrm{C}_{15: 0}(29.3 \%)$, iso- $\mathrm{C}_{17: 1} \omega 9 c(7.1 \%)$, iso$\mathrm{C}_{17: 0} 3-\mathrm{OH}(16.3 \%)$ and summed feature $4\left(\mathrm{C}_{16: 1} \omega 7 \mathrm{c} /\right.$ iso$\left.\mathrm{C}_{15: 0} 2-\mathrm{OH}, 19.4 \%\right)$. Minor amounts of saturated fatty acids were present: anteiso- $\mathrm{C}_{15: 0}(0.6 \%), \mathrm{C}_{16: 0}(2.7 \%)$, anteiso- $\mathrm{C}_{17: 0}(3.1 \%), \mathrm{C}_{18: 0}(1.2 \%), \mathrm{C}_{15: 0} 3-\mathrm{OH}(3.7 \%)$ and $\mathrm{C}_{16: 0} 3-\mathrm{OH}(2.3 \%)$.

Strain DCY $14^{\mathrm{T}}$ contained menaquinones with seven and 13 isoprene units (MK-7 and MK-13), with MK-7 as the predominant quinone. MK-7 is commonly found amongst species of the family Sphingobacteriaceae (Steyn et al., 1998).
The 16S rRNA gene sequence determined for strain DCY $14^{\mathrm{T}}$ was a continuous stretch of $1468 \mathrm{nt}$. The $16 \mathrm{~S}$ rRNA gene sequences of related taxa were obtained from GenBank. Strain $\mathrm{DCY}_{14}{ }^{\mathrm{T}}$ was shown to belong to the class Sphingobacteria (order Sphingobacteriales, family Sphingobacteriaceae). The highest level of sequence similarity was found with respect to Parapedobacter koreensis Jip $14^{\mathrm{T}}$ (95.8\% similarity). The phylogenetic tree (Fig. 1) shows clearly that strain DCY $14^{\mathrm{T}}$ belongs to the lineage of the family Sphingobacteriaceae, as evidenced by the high level of bootstrap support. On the basis of the 16S rRNA gene sequencing data, the phylogenetic position of strain DCY $14^{\mathrm{T}}$ among members of the family Sphingobacteriaceae is unique and distinct.

The G + C content of the genomic DNA of strain DCY $14^{\mathrm{T}}$ was found to be $50.1 \mathrm{~mol} \%$, this being higher than the contents for known species within the family Sphingobacteriaceae.

On the basis of the phenotypic, chemotaxonomic and phylogenetic data, strain DCY $14^{\mathrm{T}}$ represents a novel species of the genus Pedobacter (family Sphingobacteriaceae), for which the name Pedobacter soli sp. nov. is proposed.

\section{Description of Parapedobacter soli sp. nov.}

Parapedobacter soli (so'li. L. neut. gen. n. soli of soil, the source of the type strain).

Cells grown on $\mathrm{R} 2 \mathrm{~A}$ agar at $30{ }^{\circ} \mathrm{C}$ for 5 days are Gramnegative, aerobic, non-motile rods. Colonies grown on R2A agar for 5 days are circular and yellow. Optimal growth temperature on trypticase soy agar is $30{ }^{\circ} \mathrm{C}$. Oxidase- and catalase-positive. Produces $N$-acetyl- $\beta$-glucosaminidase, acid phosphatase, alkaline phosphatase, esterase (C4), esterase (C8), $\alpha$-galactosidase, $\beta$-galactosidase, $\alpha$-glucosidase, $\beta$-glucosidase, leucine arylamidase, $\alpha$-mannosidase and naphthol-AS-BI-phosphohydrolase but does not

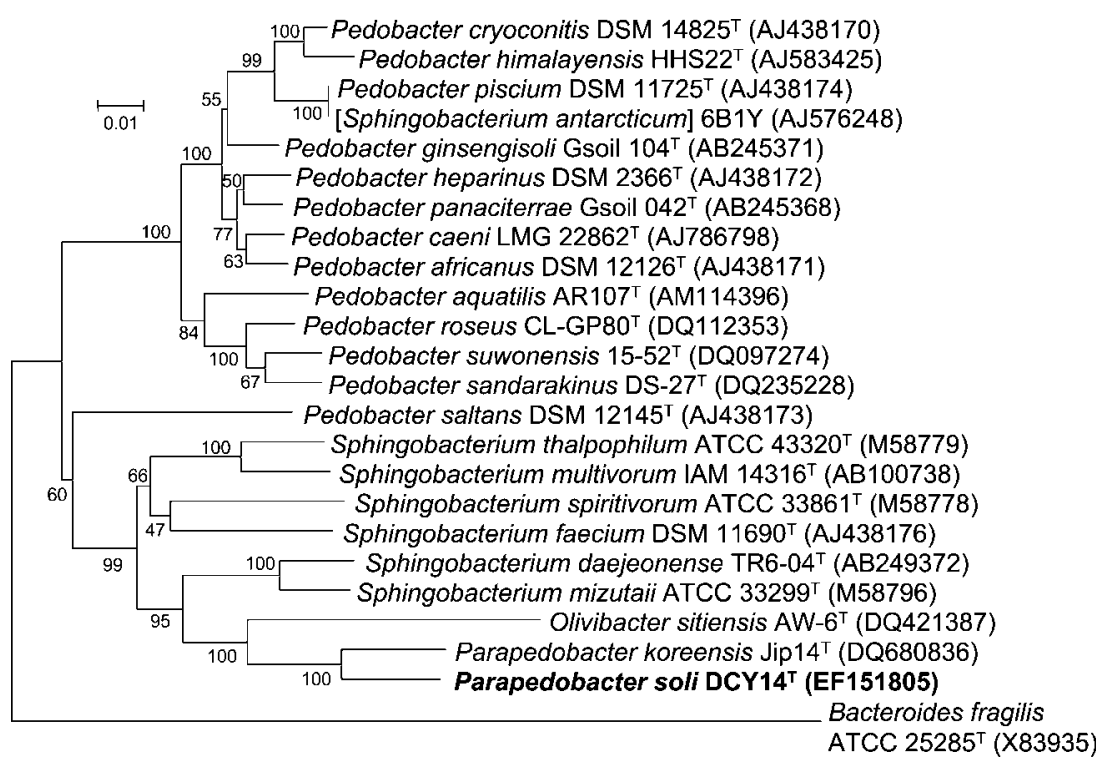

Fig. 1. Neighbour-joining phylogenetic tree, based on 16S rRNA gene sequences, showing the phylogenetic relationships between strain DCY $14^{\top}$ and related species. Bar, 0.01 substitutions per nucleotide position. 
produce arginine dihydrolase, $\alpha$-chymotrypsin, cystine arylamidase, $\alpha$-fucosidase, $\beta$-glucuronidase, lipase (C14), protease (gelatin hydrolysis), trypsin, urease or valine arylamidase. Assimilates L-arabinose, D-glucose, maltose, D-mannose, melibiose, L-rhamnose, D-ribose, sucrose, Dmannitol, D-sorbitol, $N$-acetyl-D-glucosamine, salicin and glycogen. Does not assimilate 2-ketogluconate, 3-hydroxybenzoate, 3-hydroxybutyrate, 4-hydroxybenzoate, 5ketogluconate, acetate, adipate, caprate, citrate, gluconate, itaconate, DL-lactate, L-malate, malonate, phenylacetate, propionate, suberate, n-valerate, L-fucose, myo-inositol, Lalanine, L-histidine, L-proline or L-serine. DNA G+C content is $50.1 \mathrm{~mol} \%$ (as determined by HPLC). The predominant quinone is MK-7. The major cellular fatty acids include anteiso- $\mathrm{C}_{13: 0}(11.4 \%)$, iso- $\mathrm{C}_{15: 0}(29.3 \%)$, iso- $\mathrm{C}_{17: 1} \omega 9 c \quad(7.1 \%)$, iso- $\mathrm{C}_{17: 0} \quad 3-\mathrm{OH} \quad(16.3 \%)$ and summed feature $4\left(\mathrm{C}_{16: 1} \omega 7 c /\right.$ iso- $\left.\mathrm{C}_{15: 0} 2-\mathrm{OH}, 19.4 \%\right)$. Minor saturated fatty acids anteiso- $\mathrm{C}_{15: 0}(0.6 \%), \mathrm{C}_{16: 0}$ $(2.7 \%)$, anteiso- $\mathrm{C}_{17: 0}(3.1 \%), \mathrm{C}_{18: 0}(1.2 \%), \mathrm{C}_{15: 0} 3-\mathrm{OH}$ $(3.7 \%)$ and $\mathrm{C}_{16: 0} 3-\mathrm{OH}(2.3 \%)$ are present. Nitrate is not reduced to either nitrite or nitrogen gas.

The type strain, DCY $14^{\mathrm{T}}\left(=\right.$ KCTC $\left.12984^{\mathrm{T}}=\mathrm{LMG} 24069^{\mathrm{T}}\right)$, was isolated from soil from a ginseng field near Daejeon, South Korea.

\section{Acknowledgements}

This work was supported by a Korea Science and Engineering Foundation (KOSEF) grant funded by the Korean Government (MOST) (no. R01-2006-000-11178-0) and by a BK21 research fellowship from the Korean Ministry of Education and Human Resource Development.

\section{References}

Buck, J. D. (1982). Nonstaining ( $\mathrm{KOH})$ method for determination of Gram reactions of marine bacteria. Appl Environ Microbiol 44, 992-993.

Collins, M. D. \& Jones, D. (1981). Distribution of isoprenoid quinone structural types in bacteria and their taxonomic implications. Microbiol Rev 45, 316-354.

Felsenstein, J. (1985). Confidence limits on phylogenies: an approach using the bootstrap. Evolution 39, 783-791.

Hall, T. A. (1999). BioEdit: a user-friendly biological sequence alignment editor and analysis program for Windows 95/98/NT. Nucleic Acids Symp Ser 41, 95-98.

Kim, M. K., Im, W.-T., Ohta, H., Lee, M. \& Lee, S.-T. (2005). Sphingopyxis granuli sp. nov., a $\beta$-glucosidase-producing bacterium in the family Sphingomonadaceae in $\alpha-4$ subclass of the Proteobacteria. J Microbiol 43, 152-157.
Kim, M. K., Na, J.-R., Cho, D. H., Soung, N. K. \& Yang, D.-C. (2007). Parapedobacter koreensis gen. nov., sp. nov. Int J Syst Evol Microbiol 57, 1336-1341.

Kimura, M. (1983). The Neutral Theory of Molecular Evolution. Cambridge: Cambridge University Press.

Kumar, S., Tamura, K., Jakobsen, I. B. \& Nei, M. (2001). MEGA2: molecular evolutionary genetics analysis software. Bioinformatics 17, 1244-1245.

Mesbah, M., Premachandran, U. \& Whitman, W. B. (1989). Precise measurement of the $\mathrm{G}+\mathrm{C}$ content of deoxyribonucleic acid by high-performance liquid chromatography. Int J Syst Bacteriol 39, 159-167.

Ntougias, S., Fasseas, C. \& Zervakis, G. I. (2007). Olivibacter sitiensis gen. nov., sp. nov., isolated from alkaline olive-oil mill wastes in the region of Sitia, Crete. Int J Syst Evol Microbiol 57, 398-404.

Saitou, N. \& Nei, M. (1987). The neighbor-joining method: a new method for reconstructing phylogenetic trees. Mol Biol Evol 4, 406-425.

Sasser, M. (1990). Identification of bacteria by gas chromatography of cellular fatty acids, MIDI Technical Note 101. Newark, DE: MIDI Inc.

Shin, Y. K., Lee, J.-S., Chun, C. O., Kim, H.-J. \& Park, Y.-H. (1996). Isoprenoid quinone profiles of the Leclercia adecarboxylata KCTC $1036^{\mathrm{T}}$. J Microbiol Biotechnol 6, 68-69.

Steyn, P. L., Segers, P., Vancanneyt, M., Sandra, P., Kersters, K. \& Joubert, J. J. (1998). Classification of heparinolytic bacteria into a new genus, Pedobacter, comprising four species: Pedobacter heparinus comb. nov., Pedobacter piscium comb. nov., Pedobacter africanus sp. nov. and Pedobacter saltans sp. nov. Proposal of the family Sphingobacteriaceae fam. nov. Int J Syst Bacteriol 48, 165-177.

Takeuchi, M. \& Yokota, A. (1992). Proposals of Sphingobacterium faecium sp. nov., Sphingobacterium piscium sp. nov., Sphingobacterium heparinum comb. nov., Sphingobacterium thalpophilum comb. nov. and two genospecies of the genus Sphingobacterium, and synonymy of Flavobacterium yabuuchiae and Sphingobacterium spiritivorum. J Gen Appl Microbiol 38, 465-482.

Tamaoka, J. \& Komagata, K. (1984). Determination of DNA base composition by reversed-phase high-performance liquid chromatography. FEMS Microbiol Lett 25, 125-128.

Thompson, J. D., Gibson, T. J., Plewniak, F., Jeanmougin, F. \& Higgins, D. G. (1997). The CLUSTAL_X windows interface: flexible strategies for multiple sequence alignment aided by quality analysis tools. Nucleic Acids Res 25, 4876-4882.

Weisburg, W. G., Barns, S. M., Pelletier, D. A. \& Lane, D. J. (1991). $16 \mathrm{~S}$ ribosomal DNA amplification for phylogenetic study. J Bacteriol 173, 697-703.

Yabuuchi, E., Kaneko, T., Yano, I., Moss, C. W. \& Miyoshi, N. (1983). Sphingobacterium gen. nov., Sphingobacterium spiritivorum comb. nov., Sphingobacterium multivorum comb. nov., Sphingobacterium mizutae sp. nov., and Flavobacterium indologenes sp. nov.: glucosenonfermenting gram-negative rods in CDC groups IIk-2 and IIb. Int J Syst Bacteriol 33, 580-598. 